University of Nebraska - Lincoln

DigitalCommons@University of Nebraska - Lincoln

Publications, Agencies and Staff of the U.S.

Department of Commerce

U.S. Department of Commerce

2011

\title{
The effect of stimulation frequency on the transmural ventricular monophasic action potential in yellowfin tuna Thunnus albacares
}

\author{
S. M. Patrick \\ University of Manchester \\ E. White \\ University of Leeds \\ R. W. Brill \\ NOAA Fisheries \\ H. A. Shiels \\ University of Manchester
}

Follow this and additional works at: https://digitalcommons.unl.edu/usdeptcommercepub

Part of the Environmental Sciences Commons

Patrick, S. M.; White, E.; Brill, R. W.; and Shiels, H. A., "The effect of stimulation frequency on the transmural ventricular monophasic action potential in yellowfin tuna Thunnus albacares" (2011). Publications, Agencies and Staff of the U.S. Department of Commerce. 304.

https://digitalcommons.unl.edu/usdeptcommercepub/304

This Article is brought to you for free and open access by the U.S. Department of Commerce at DigitalCommons@University of Nebraska - Lincoln. It has been accepted for inclusion in Publications, Agencies and Staff of the U.S. Department of Commerce by an authorized administrator of DigitalCommons@University of Nebraska - Lincoln. 


\title{
The effect of stimulation frequency on the transmural ventricular monophasic action potential in yellowfin tuna Thunnus albacares
}

\author{
S. M. Patrick*, E. White†, R. W. Brill $\ddagger$ And H. A. Shiels* $\S$ \\ *Faculty of Life Sciences, University of Manchester, 46 Grafton Street, Core \\ Technology Facility, Manchester M13 9NT, U.K., †Institute of Membrane and \\ Systems Biology, The University of Leeds, Leeds LS2 9JT, U.K. and $\$$ Cooperative \\ Marine Education and Research Program, NOAA Fisheries, Northeast Fisheries \\ Science Center, Virginia Institute of Marine Science, P. O. Box 1346, Gloucester \\ Point, VA 23062, U.S.A.
}

(Received 14 May 2010, Accepted 3 November 2010)

\begin{abstract}
Monophasic action potentials (MAPs) were recorded from the spongy and compact layers of the yellowfin tuna Thunnus albacares ventricle as stimulation frequency was increased. MAP duration decreased with increase in stimulation frequency in both the spongy and compact myocardial layers, but no significant difference in MAP duration was observed between the layers. (c) 2011 The Authors Journal of Fish Biology ๑ 2011 The Fisheries Society of the British Isles
\end{abstract}

Key words: compact myocardium; endocardium; epicardium; heterogeneity; interval-duration relationship; spongy myocardium.

The ventricles of active fish species have a morphologically distinct outer compact myocardium and an inner spongy myocardium. Although the relative proportion each layer contributes to total myocardial mass has been quantified in a number of species and described in great morphological detail (Santer et al., 1983; Tota et al., 1983; Icardo et al., 2002), there has been little comparison of their electrical properties. In the tunas (family Scombridae), the heart is relatively large and has a high proportion of compact myocardium (40-70\%) that is morphologically distinct from the spongy myocardium (Agnisola \& Tota, 1994). This makes large scombrids such as tunas excellent models to investigate regional variations in myocardial electrical properties. Differences in action potential duration (APD) between various ventricular regions (e.g. epicardium and endocardium) of the mammalian heart have been described, and exaggeration of these differences can lead to potentially lethal re-entrant arrhythmias (Antzelevitch, 2005). Myocardial layer-specific action potential characterization has not been made for the fish heart. The primary aim of this study was to investigate

§Author to whom correspondence should be addressed. Tel.: +44 (0) 161275 5092; email: holly.shiels@manchester.ac.uk 
the transmural heterogeneity in the ventricular monophasic action potential (MAP) of the yellowfin tuna Thunnus albacares (Bonnaterre) and assess its modulation by stimulation frequency.

MAPs are waveforms recorded extracellularly that accurately reproduce the repolarization time course of the transmembrane action potential (Franz, 1999; Knollmann et al., 2001). They differ from electrocardiograms (ECGs) because they only measure the electrical activity of a small group of cells under the active electrode and not the electrical activity of the whole heart. The MAP recordings described in this study were made by pressing a contact electrode against the epicardium or endocardium, while a second electrode acted as the reference electrode. The pressure exerted on the myocardium by the contact electrode deactivates sodium channels, reducing excitation and thereby providing a 'frozen' potential in contrast to the potential found in the unaffected adjacent cells. Therefore, a temporal electrical gradient is produced between the depolarized cells around the electrode and the adjacent cells. This electrical gradient reflects the repolarization time course of mammalian cardiac action potentials with high fidelity (Franz, 1999). The amplitude of a MAP recording, however, depends on contact pressure and tissue type and does not correspond to the amplitude of an intracellular action potential (Franz, 1999).

MAPs can be recorded from different regions and different layers of beating heart preparations and have been widely used in mammalian cardiac research (Babuty \& Lab, 2001; Tsuburaya et al., 2007). The use of MAPs as faithful representations of the transmembrane action potential time course in the heart of the rainbow trout Oncorhynchus mykiss (Walbaum) has been recently validated (Patrick et al., 2010). In this study, MAP recordings were made from a scombrid (T. albacares) heart to assess the ventricular transmural electrical heterogeneity and the impact of pacing frequency.

Thunnus albacares ( $n=4$, mean \pm S.E. $3.9 \pm 0.8 \mathrm{~kg}$ ) were caught in the central north Pacific (in proximity to the Hawaiian Islands) using standard trawling gear and longline techniques. The experiments were performed in shipboard laboratory facilities. Fish were sacrificed by pithing, the heart was removed and placed in oxygenated physiological saline consisting of (in mmol $1^{-1}$ ): $185.7 \mathrm{NaCl}, 1 \cdot 1$ $\mathrm{MgCl}_{2}, 7.0 \mathrm{KCl}, 3.22 \mathrm{CaCl}_{2}, 10$ sodium pyruvate and $10 \mathrm{Hepes}$; $\mathrm{pH}$ of 7.7 with $\mathrm{NaOH}$ at $23^{\circ} \mathrm{C}$. The majority of atrium was excised to remove myogenic stimulation but the atrioventricular node was left intact. The heart was placed in a modified Langendorff preparation with the bulbus arteriosus cannulated and perfused with oxygenated saline at $23^{\circ}$ C. Flow was set to $c .25 \mathrm{ml} \mathrm{min}{ }^{-1} \mathrm{~kg}^{-1}$ by varying input pressure. Output pressure was ambient (i.e. $0 \mathrm{kPa}$ ). The coronary artery was also cannulated and perfused with oxygenated saline. Platinum stimulation electrodes were positioned at the atrioventricular junction to ensure proximity to any remaining atrioventricular node tissue. The heart was stimulated to contract at various frequencies with a $10 \mathrm{~ms}$ square stimulating pulse $1.5 \mathrm{~V}$ above threshold strength (Student Stimulator, Grass Instruments; www.grasstechnologies.com). All hearts were paced at $0.6 \mathrm{~Hz}$ until a stable MAP reading was attained; stimulation frequency was then decreased to $0.4 \mathrm{~Hz}$, returned to $0.6 \mathrm{~Hz}$ and then increased to $0.8 \mathrm{~Hz}$. The stimulation frequency was then returned to $0.6 \mathrm{~Hz}$ to assess any change in the preparation over time. It was not possible to consistently pace the isolated heart at frequencies higher than $0.8 \mathrm{~Hz}$, suggesting that under the conditions of the experiment the refractory period of the hearts was $c .1040 \mathrm{~ms}$. Although 
$0.8 \mathrm{~Hz}$ is below the often reported range of Thunnini heart rates $(1.5-4 \mathrm{~Hz}$; Brill \& Bushnell, 2001) and slightly below the in situ heart rate reported by Blank et al. (2002) (c. $1 \cdot 1 \mathrm{~Hz}$ at $\left.23^{\circ} \mathrm{C}\right)$, a recent in vivo study on free-swimming southern bluefin tuna Thunnus maccoyii (Castlenau) reported heart rates in the range of $0.34-0.84 \mathrm{~Hz}$ (Clark et al., 2008). These data suggest that the frequencies of $0.4-0.8 \mathrm{~Hz}$ lie within a physiological range for Thunnus spp. at similar temperatures.

Two types of MAP electrodes were tested in this study. The first was a 'suction' electrode based on Runnalls et al. (1987). Briefly, the contact electrode was made from an $\mathrm{Ag}-\mathrm{AgCl}$ pellet (Harvard Apparatus; www.harvardapparatus.co.uk) and fed into a microelectrode holder of slightly larger diameter (Harvard Apparatus). The reference electrode, also an $\mathrm{Ag}-\mathrm{AgCl}$ pellet, was positioned in a hole cut into the side of the holder. Tubing was attached to the side arm and once pressed against the heart 'suction' was provided around the contact electrode by a syringe attached to the tubing. A three-way stopcock allowed 'suction' to be maintained at a constant level. The second type of electrode, based on Knollmann et al. (2001), was constructed from two silver wires ( $95 \%$ purity) $0.25 \mathrm{~mm}$ in diameter. The wires were insulated up to $1 \mathrm{~mm}$ from the tips by Teflon sleeves, twisted around each other and $3 \mathrm{~mm}$ of the distal ends bent by $90^{\circ}$ to enhance flexibility. The reference electrode was placed $1 \mathrm{~mm}$ proximal from the contact electrode to avoid simultaneous contact with the myocardium. Electrode tips were chlorinated in bleach overnight to prevent direct current offset (Knollmann et al., 2001).

To record MAPs with the 'suction' electrodes, a vacuum seal was created on the epicardial surface of the compact layer. Measurements recorded with the wire electrodes were obtained by pressing the contact electrode slightly into the cardiac tissue. Therefore, it is probable that both the pellet and wire electrodes were acting as contact MAP electrodes (Franz, 1999). Spongy myocardial readings were taken with both electrodes by feeding the electrode into the ventricle through the atrioventricular junction and pressing the electrode against the endocardial wall. The powerful contractions of the ventricle hindered the vacuum seal of the pellet electrodes, which prevented accurate recordings. The wire electrodes gave more stable MAP recordings and were used as the preferred method.

The electrodes were connected to an ml136 bio amp (ADInstruments Ltd; www. adinstruments.com) and Powerlab/4sp data acquisition system (ADInstruments Ltd). Groups of 12 MAPs from each stimulation frequency were averaged and the monophasic action potential duration (MAPD) at 25, 50 and 90\% repolarization (MAPD25, MAPD50 and MAPD90) was calculated using Clampfit 9.0 (Molecular Devices; www.moleculardevices.com). Significant differences between tissue layers paced at different frequencies were assessed using two-way repeated measures ANOVA (RM ANOVA) followed by Student-Newman-Keuls post hoc tests. $P<0.05$ indicated a significant difference.

Examples of MAPs recorded from both the compact and spongy myocardium at $0.4 \mathrm{~Hz}$ and $0.8 \mathrm{~Hz}$ are given in Fig. 1. The decrease in MAPD due to an increased pacing frequency can be clearly seen for both myocardial layers. Mean data for percentage change in MAPD25, MAPD50 and MAPD90 for each of the frequencies are given in Fig. 2. The raw data are provided in Table I. No significant difference in MAPD was found between the two myocardial layers at any level of repolarization or pacing frequency. 
(a)

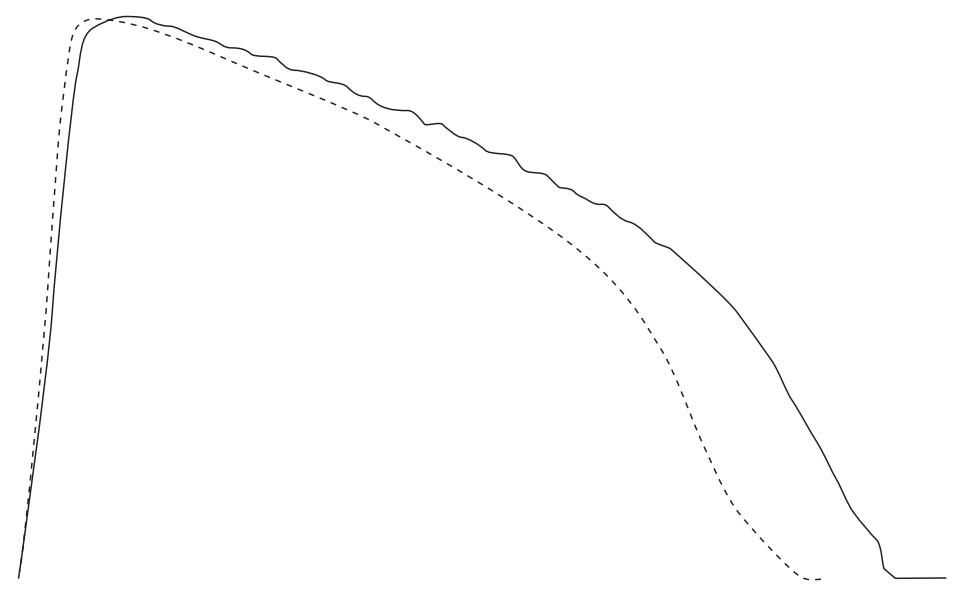

(b)

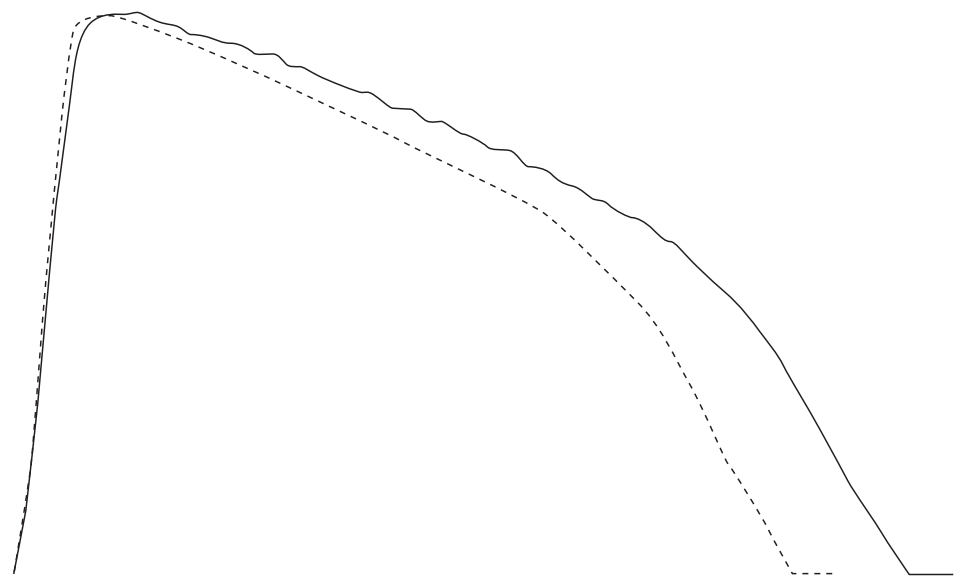

$50 \mathrm{~ms}$

FIG. 1. Representative recordings of monophasic action potentials (MAPs) from the (a) spongy myocardium and (b) compact myocardium of the Thunnus albacares ventricle. Traces are the average of four recordings at a pacing frequency of $0.4 \mathrm{~Hz}\left({ }_{-}\right)$and $0.8 \mathrm{~Hz}\left({ }_{-}\right)_{-}$. The $y$-axis has been normalized for both recordings.

The present investigation into the relationship between pacing frequency and MAPD in T. albacares found that MAPD is inversely proportional to pacing frequency. This phenomenon, known as the interval-duration relationship, has been previously described in both mammals and fishes (Liu \& Antzelevitch, 1995; Harwood et al., 2000; Hanton et al., 2001). The exact mechanism underlying the intervalduration relationship is unknown, but may involve incomplete decay of the delayed rectifier currents (Katz, 2006). Both Vornanen et al. (2002) and Galli et al. (2009) found evidence for a strong delayed rectifier current $\left(I_{\mathrm{kr}}\right)$ in $O$. mykiss and pacific bluefin tuna Thunnus orientalis (Temminck \& Schlegel) heart, respectively, and it is plausible that this current also underlies the interval-duration relationship in $T$. albacares. A similar decrease in APD with increased stimulation frequency has 

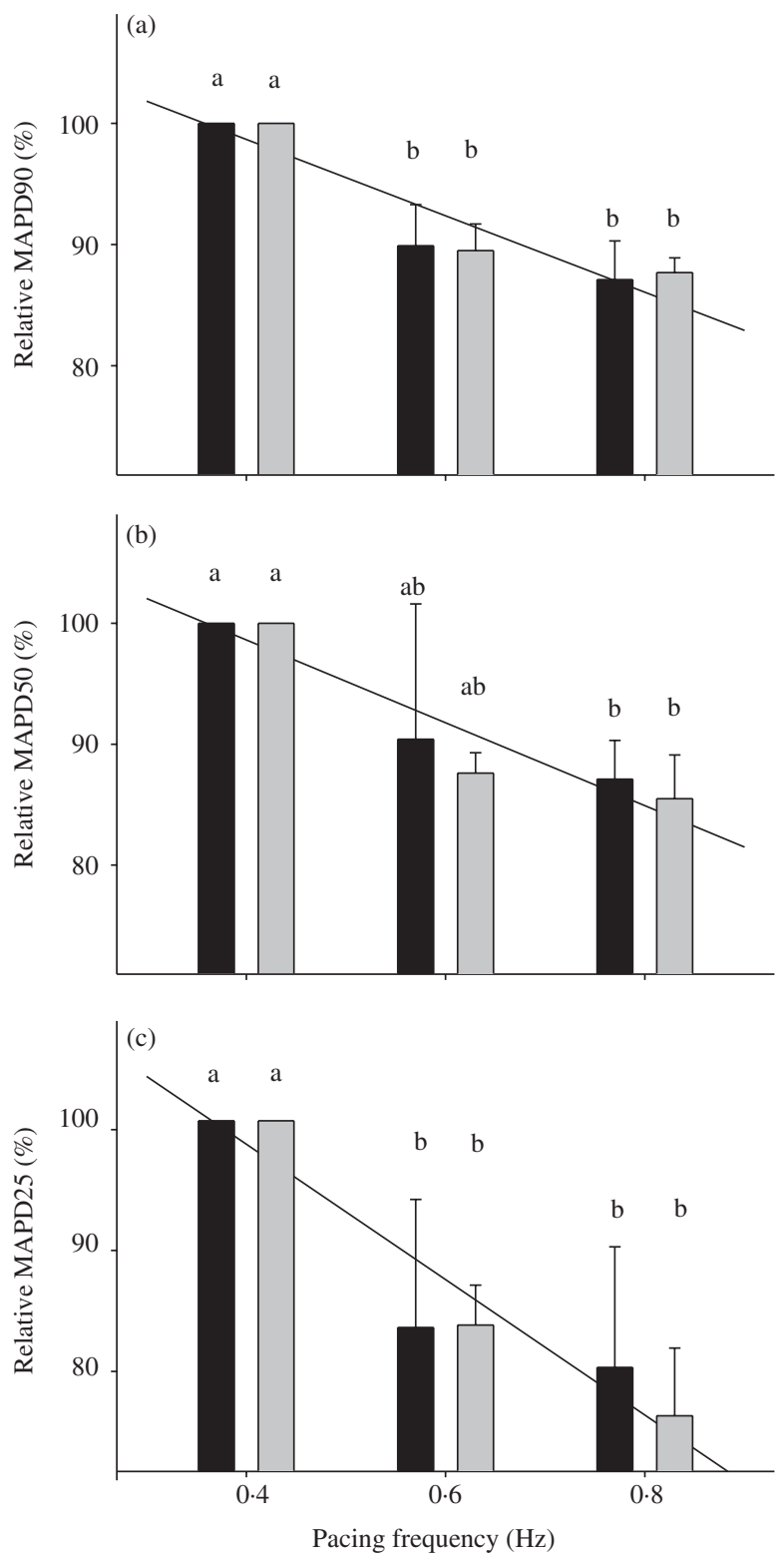

FIG. 2. The effect of frequency on monophasic action potential duration (MAPD) in the spongy ( $\square$ ) and compact $(\square)$ ventricular myocardium from Thunnus albacares $(n=4)$. The effect of frequency on MAPD is expressed as a percentage change from the normalized value at $0.4 \mathrm{~Hz}$ for (a) 25 , (b) 50 and (c) 90\% repolarization duration (MAPD25, MAPD50 and MAPD90, respectively). Differences were assessed using a two-way repeated measures ANOVA followed by Student-Newman-Keuls post hoc tests and are denoted by dissimilar lower case letters $(P<0 \cdot 05)$. MAP recordings were taken while the heart was initially paced at $0.6 \mathrm{~Hz}$, increased to $0.8 \mathrm{~Hz}$, decreased to $0.4 \mathrm{~Hz}$ and then returned to $0.6 \mathrm{~Hz}$ to assess the fatigue of the preparation. No significant differences were found between the MAPDs recorded at $0.6 \mathrm{~Hz}$ at the start and end of the experiment, therefore these data were pooled into a single set for each heart in this analysis. There were no significant differences between myocardial layers at any given frequency. 
TABLE I. The effect of pacing frequency on monophasic action potential duration (MAPD) at 25\% (MAPD25), 50\% (MAPD50) and 90\% (MAPD90) repolarization in ventricular tissue from Thunnus albacares

\begin{tabular}{|c|c|c|c|c|c|c|}
\hline \multirow{3}{*}{$\begin{array}{l}\text { Frequency } \\
(\mathrm{Hz})\end{array}$} & \multicolumn{6}{|c|}{ Absolute duration (ms) } \\
\hline & \multicolumn{3}{|c|}{ Compact myocardium } & \multicolumn{3}{|c|}{ Spongy myocardium } \\
\hline & MAPD25 & MAPD50 & MAPD90 & MAPD25 & MAPD50 & MAPD90 \\
\hline 0.4 & $131 \cdot 8 \pm 21 \cdot 2$ & $180 \cdot 9 \pm 22 \cdot 6$ & $260 \cdot 8 \pm 6 \cdot 0^{*}$ & $136 \cdot 2 \pm 22 \cdot 4$ & $195 \cdot 7 \pm 21.4$ & $254.4 \pm 19.1 *$ \\
\hline $0 \cdot 6$ & $100 \cdot 5 \pm 7.9$ & $144.5 \pm 8.3$ & $212 \cdot 2 \pm 3 \cdot 4$ & $113 \cdot 3 \pm 16 \cdot 5$ & $169 \cdot 3 \pm 13 \cdot 6$ & $222 \cdot 0 \pm 7 \cdot 6$ \\
\hline $0 \cdot 8$ & $90 \cdot 0 \pm 17 \cdot 3$ & $126 \cdot 5 \pm 18 \cdot 0$ & $211 \cdot 3 \pm 6 \cdot 5$ & $106 \cdot 2 \pm 30 \cdot 7$ & $159 \cdot 8 \pm 22 \cdot 6$ & $213.9 \pm 14.4$ \\
\hline
\end{tabular}

Values are the mean \pm S.E. of $n=4$ fish. As there were no significant differences between the MAPDs recorded at $0.6 \mathrm{~Hz}$ at the start and end of the experiment the data was pooled into a single set for each heart.

* Significant difference within columns $(P<0.05$, two-way repeated measures ANOVA with Student-Newman-Keuls post hoc analysis).

been shown in isolated myocytes from both $O$. mykiss and zebrafish Danio rerio (Hamilton) (Harwood et al., 2000; Brette et al., 2008). The former was related to a frequency-dependent decrease in the L-type $\mathrm{Ca}^{2+}$ current (Harwood et al., 2000) and this may also contribute to the effect seen in $T$. albacares heart.

No significant difference was found between MAPD in the two myocardial layers of $T$. albacares, although transmural electrophysiological heterogeneities are common in mammalian hearts (Antzelevitch, 2005). The APD of the mammalian epicardial myocyte is shorter than that of the mammalian endocardial myocyte due to differences in the type and number of ion channels present in each tissue layer (Antzelevitch et al., 1991; Nerbonne, 2000). The physiological relevance of transmural APD heterogeneity in mammals is unclear, but exaggeration of the transmural heterogeneity can lead to lethal re-entrant arrhythmias (Antzelevitch \& Fish, 2001). The lack of transmural APD heterogeneity in the fish heart may contribute to its apparent resistance to arrhythmias (Cousins \& Farrell, 1996; Patrick et al., 2010).

The delayed rectifier current $\left(I_{\mathrm{kr}}\right)$, and the transient outward current $\left(I_{\mathrm{to}}\right)$ are thought to be important for setting the APD in mammalian myocytes and can explain transmural APD heterogeneity in a number of species (Liu et al., 1993; Liu \& Antzelevitch, 1995; Katz, 2006). The lack of a transmural change in MAP shape in the T. albacares heart may indicate little regional difference in repolarizing ionic currents. No evidence was found of an $I_{\text {to }}$-like notch in the MAP from either the compact or spongy $T$. albacares myocardium, despite the fact that MAP electrodes are capable of resolving action potential notches in mammalian tissue (Franz, 1999). Electrophysiological studies of isolated myocytes from O. mykiss (Vornanen et al., 2002), D. rerio (Brette et al., 2008) and T. orientalis (Galli et al., 2009) also find no evidence of $I_{\text {to }}$, suggesting a relatively small or absent $I_{\text {to }}$ in the fish heart.

The difficulties associated with maintaining large scombrids in captivity have limited electrophysiological investigations of their ionic currents. Only two such papers are known in the literature (Shiels et al., 2004; Galli et al., 2009). Galli et al. (2009) showed that whole-cell current-clamped action potentials from isolated $T$. orientalis myocytes at $23^{\circ} \mathrm{C}$ are similar in duration $(248.0 \pm 19.8 \mathrm{~ms}$ mean \pm s.E. $)$ to the 
present MAP recordings from intact heart tissue. The upstroke of the MAP was slower than that of the intracellular action potential, which is consistent with previous comparisons of MAPs and intracellular action potentials from mammals (Babuty $\&$ Lab, 2001). The difference in upstroke velocity is thought to be related to the fact that the MAP is recorded from a small area of tissue around the MAP electrode, rather than a single myocyte, resulting in a sequential alteration in current flow across this area of tissue (Franz, 1999).

The principle findings of this study are (1) the MAP electrode can be successfully used to investigate transmural MAPDs in the hearts of large scombrids, (2) a negative interval-duration relationship exists in the T. albacares ventricle and (3) there is no difference in MAPD between the spongy and compact myocardial layers of T. albacares. Importantly, MAPs can be successfully measured at sea and therefore could be used to investigate integrated ion flow in fish hearts in the field.

The National Oceanic and Atmospheric Administration (NOAA), M. Musyl, the crew and scientists of the NOAA R.V. Oscar Elton Sette and the staff at the Kewalo Research Facility are acknowledged for their help during this research.

\section{References}

Agnisola, C. \& Tota, B. (1994). Structure and function of the fish cardiac ventricle - flexibility and limitations. Cardioscience 5, 145-153.

Antzelevitch, C. (2005). Modulation of transmural repolarization. Communicative Cardiac Cell 1047, 314-323.

Antzelevitch, C. \& Fish, J. (2001). Electrical heterogeneity within the ventricular wall. Basic Research in Cardiology 96, 517-527.

Antzelevitch, C., Sicouri, S., Litovsky, S. H., Lukas, A., Krishnan, S. C., DiDiego, J. M., Gintant, G. A. \& Liu, D. W. (1991). Heterogeneity within the ventricular wall electrophysiology and pharmacology of epicardial, endocardial, and M-cells. Circulation Research 69, 1427-1449.

Babuty, D. \& Lab, M. (2001). Heterogeneous changes of monophasic action potential induced by sustained stretch in atrium. Journal of Cardiovascular Electrophysiology 12, $323-329$.

Blank, J. M., Morrissette, J. M., Davie, P. S. \& Block, B. A. (2002). Effects of temperature, epinephrine and $\mathrm{Ca}^{2+}$ on the hearts of yellowfin tuna (Thunnus albacares). Journal of Experimental Biology 205, 1881-1888.

Brette, F., Luxan, G., Cros, C., Dixey, H., Wilson, C. \& Shiels, H. A. (2008). Characterization of isolated ventricular myocytes from adult zebrafish (Danio rerio). Biochemical and Biophysical Research Communications 374, 143-146.

Brill, R. W. \& Bushnell, P. G. (2001). The cardiovascular system of tunas. In Tunas: Physiology, Ecology and Evolution (Block, B. A. \& Stevens, E .D., eds), pp. 79-120. San Diego, CA: Academic Press.

Cousins, K. L. \& Farrell, A. P. (1996). Stretch-induced release of atrial natriuretic factor from the heart of rainbow trout (Oncorhynchus mykiss). Canadian Journal of Zoology 74, 380-387.

Clark, T. D., Taylor, B. D., Seymour, R. S., Ellis, D., Buchanan, J., Fitzgibbon, Q. P. \& Frappell, P. B. (2008). Moving with the beat: heart rate and visceral temperature of free-swimming and feeding bluefin tuna. Proceedings of the Royal Society B 275, $2841-2850$.

Franz, M. R. (1999). Current status of monophasic action potential recording: theories, measurements and interpretations. Cardiovascular Research 41, 25-40.

Galli, G. L. J., Lipnick, M. S. \& Block, B. A. (2009). Effect of thermal acclimation on action potentials and sarcolemmal $\mathrm{K}^{+}$channels from Pacific bluefin tuna cardiomyocytes. American Journal of Physiology 297, R502-R509. 
Hanton, G., Nahas, K., Priou, C., Rabemampianina, Y. \& Baneux, P. (2001). The QT interval in the dog ECG: importance in preclinical toxicology and relationship to heart rate. Toxicology Methods 11, 21-40.

Harwood, C. L., Howarth, F. C., Altringham, J. D. \& White, E. (2000). Rate-dependent changes in cell shortening, intracellular $\mathrm{Ca}^{2+}$ levels and membrane potential in single, isolated rainbow trout (Oncorhynchus mykiss) ventricular myocytes. Journal of Experimental Biology 203, 493-504.

Icardo, J. M., Colvee, E., Cerra, M. C. \& Tota, B. (2002). The structure of the conus arteriosus of the sturgeon (Acipenser naccarii) heart: II. The myocardium, the subepicardium, and the conus-aorta transition. Anatomical Record 268, 388-398.

Katz, A. M. (2006) Physiology of the Heart, 4th edn. Philadelphia, PA: Lippincott Williams \& Wilkins.

Knollmann, B. C., Katchman, A. N. \& Franz, M. R. (2001). Monophasic action potential recordings from intact mouse heart: validation, regional heterogeneity, and relation to refractoriness. Journal of Cardiovascular Electrophysiology 12, 1286-1294.

Liu, D. W. \& Antzelevitch, C. (1995). Characteristics of the delayed rectifier current (IKr and IKs) in canine ventricular epicardial, midmyocardial, and endocardial myocytes: a weaker IKs contributes to the longer action potential of the M cell. Circulation Research 76, 351-365.

Liu, D. W., Gintant, G. A. \& Antzelevitch, C. (1993). Ionic bases for electrophysiological distinctions among epicardial, midmyocardial, and endocardial myocytes from the free wall of the canine left ventricle. Circulation Research 72, 671-687.

Nerbonne, J. M. (2000). Molecular basis of functional voltage-gated $\mathrm{K}^{+}$channel diversity in the mammalian myocardium. Journal of Physiology 525, 285-298.

Patrick, S. M., White, E. \& Shiels H. S. (2010). Mechano-electric feedback in the fish heart. PLOS ONE 5, e10548.

Runnalls, M. E., Sutton, P. M. I., Taggart, P. \& Treasure, T. (1987). Modifications of electrode design for recording monophasic action potentials in animals and humans. American Journal of Physiology 253, H1315-H1320.

Santer, R. M., Walker, M. G., Emerson, L. \& Witthames, P. R. (1983). On the morphology of the heart ventricle in marine teleost fish (Teleostei). Comparative Biochemistry and Physiology A 76, 453-457.

Shiels, H. A., Blank, J. M., Farrell, A. P. \& Block, B. A. (2004). Electrophysiological properties of the L-type $\mathrm{Ca}(2+)$ current in cardiomyocytes from bluefin tuna and Pacific mackerel. American Journal of Physiology 286, R659-R668.

Tota, B., Cimini, V., Salvatore, G. \& Zummo, G. (1983). Comparative study of the arterial and lacunary systems of the ventricular myocardium of elasmobranch and teleost fishes. American Journal of Anatomy 167, 15-32.

Tsuburaya, R., Yasuda, S., Ito, Y., Shinoto, T., Ito, K., Soma, M. \& Shimokawa, H. (2007). Long-term treatment with eicosapentaenoic acid suppresses ventricular fibrillation in a porcine model of acute myocardial infarction: in vivo analysis using monophasic action potential. Circulation 116, 725-725.

Vornanen, M., Ryökkynen, A. \& Nurmi, A. (2002). Temperature-dependent expression of sarcolemmal $\mathrm{K}+$ currents in rainbow trout atrial and ventricular myocytes. American Journal of Physiology 282, R1191-R1199. 